\title{
COMPOSIÇÃO CENTESIMAL E DE MINERAIS DE MARISCOS CRUS E COZIDOS DA CIDADE DE NATAL/RN ${ }^{1}$
}

\author{
Lucia de Fátima Campos PEDROSA ${ }^{2, *}$, Silvia Maria Franciscato COZZOLINO ${ }^{3}$
}

\begin{abstract}
RESUMO
Este estudo teve como objetivo analisar a composição centesimal e os teores de zinco, cobre e ferro de cinco tipos de mariscos crus e cozidos: Camarão (Penaeus brasiliensis), Caranguejo (Ucides cordatus), Lagosta (Panulirus argus), Ostra (Crassostrea rhizophorae) e Mexilhão (Anomalocardia brasiliana), crus e cozidos, provenientes da cidade de Natal/RN. As amostras da parte comestível de cada alimento foram adquiridas em peixaria do cais do porto. Os mariscos foram considerados fontes expressivas de proteínas e minerais, enquanto as quantidades de lipídeos e calorias foram baixas. Observou-se na maioria das amostras teores de proteínas e de cinzas aumentados após a cocção. A concentração de zinco foi variada, apresentando-se a ostra como a maior fonte dentre as espécies estudadas. Os maiores teores de ferro e cobre foram verificados no mexilhão e na ostra. A cocção provocou perdas de $50 \%$ de cobre no mexilhão e praticamente não alterou as concentrações do referido nutriente no caranguejo. Esperamos que estes resultados contribuam para bancos de dados que auxiliarão na melhor estimativa de consumo de nutrientes em inquéritos dietéticos.
\end{abstract}

Palavras-chave: composição de alimentos; minerais; mariscos; cocção de alimentos.

\section{SUMMARY}

CENTESIMAL AND MINERAL COMPOSITION OF THE RAW AND COOKED SHELLFISHES OF THE NATAL-RN CITY. The aim of this study was to analyse the centesimal composition as well as zinc, copper and iron contents of the five species from raw and cooked shellfishes: shrimp (Penaeus brasiliensis), crab (Ucides cordatus), lobster (Panulirus argus), oyster (Crassostrea rhizophorae) and mussel (Anomalocardia brasiliana). The edible samples were collected in the fish market of the Natal city. Shellfishes were considered an expressive source of the proteins and minerals, while quantities of lipids and calories were low. After the cooking process protein and ash concentration increased in most of shellfishes. Zinc analysis showed variable concentration in the species. Oyster was the food with the highest zinc values. Mussel was considered the best source of iron and copper but around $50 \%$ of the copper detected was lost after decoction. This behavior was not observed in crab samples. These results can contribute to food composition table and evaluation of the Brazilian diets.

Keywords: food composition; minerals; shellfish; cooked food.

${ }^{1}$ Recebido para publicação em 20/10/99. Aceito para publicação em 28/05/01.

2 Profa Adjunta do Departamento de Nutrição da Universidade Federal do Rio Grande do Norte. End.: Universidade Federal do Rio Grande do Norte. Centro de Ciências da Saúde. Departamento de Nutrição. Av. Gal. Cordeiro Farias S/N - Petrópolis CEP: 59100-180 - Natal/RN. Tel. (0xx84) 2154330 - Fax: (0xx84) 215.4323.E-mail: Ipedrosa@ufrnet.br

${ }^{3}$ Prof ${ }^{a}$ Titular do Departamento de Alimentos e Nutrição Experimental da Faculdade de Ciências Farmacêuticas da Universidade de São Paulo.

${ }^{*}$ A quem a correspondência deve ser enviada.

\section{1 - INTRODUÇÃO}

Os mariscos são alimentos usualmente consumidos nas regiões costeiras, de importância nutricional destacável por serem fontes alimentares de proteínas e de minerais.

Dados sobre conteúdo de minerais em alimentos, especificamente micronutrientes como zinco, ferro, cobre e selênio, são escassos nos bancos de dados de composição de alimentos [8]. O zinco é um mineral essencial para várias funções orgânicas, com recomendações de ingestão diárias definidas [6], mas a adequação dietética de ingestão é difícil de se mensurar, devido às limitações nas tabelas e programas informatizados de cálculo de dietas. Neste aspecto, alguns estudos sugerem que a forma orgânica do zinco em ostras, é tão biodisponível quanto o ferro hemínico das carnes [7].

O cobre é um elemento imprescindível ao organismo, pela sua função como componente de cuproenzimas, e, por outro lado, torna-se preocupante as altas ingestões sabendo-se das interações possíveis com outros minerais, carboidratos e da sua função como indutor da peroxidação lipídica [10].

O ferro é um micronutriente importante na nutrição humana, e devido aos altos índices de anemias carenciais em nossa população, tem sido bastante utilizado em programas de fortificação de alimentos [9]. Devido a estas práticas, o conhecimento do teor original de ferro nos alimentos torna-se indispensável.

O tipo de processamento, mesmo caseiro, também pode alterar o conteúdo e valor nutritivo dos alimentos, tornando-se importante o conhecimento destas alterações. Assim, a composição de alimentos crus e cozidos, torna-se indispensável para a análise de dietas [4]. Por estas razões, definimos analisar a composição centesimal e de minerais, de cinco tipos de mariscos, crus e cozidos, usualmente consumidos na cidade de Natal/RN.

\section{2 - MATERIAL E MÉTODOS}

\section{1 - Amostras}

Foi analisada a composição centesimal e de minerais ( $\mathrm{Zn}, \mathrm{Cu}$ e $\mathrm{Fe}$ ) de 05 (cinco) tipos de mariscos: Camarão (Penaeus brasiliensis), Caranguejo (Ucides cordatus), Lagosta (Panulirus argus), Ostra (Crassostrea rhizophorae) e Mexilhão (Anomalocardia brasiliana), crus e cozidos, provenientes da cidade de Natal - RN.

As amostras da parte comestível de cada alimento foram adquiridas em uma peixaria do cais do porto, 
sem casca e congeladas, pesando em torno de $1 \mathrm{~kg}$; e acondicionadas em sacos plásticos à temperatura de $-20^{\circ} \mathrm{C}$.

\section{2 - Preparo das amostras - cocção}

Os mariscos foram descongelados, metade da quantidade total das amostras foi cozida em água e sal, da forma usual da região, em tempos de fervura distintos para cada tipo, considerado-se a textura característica atingida (Tabela 1). Em seguida, as amostras cruas e cozidas foram secas em estufa ventilada a $60^{\circ} \mathrm{C}$, trituradas e homogeneizadas em moinho de pás. Precedente à realização das análises descritas nos ítens 2.3 e 2.4 o material seco foi homogeneizado em graal e submetido à determinação da umidade residual a $105^{\circ} \mathrm{C}$.

TABELA 1. Tempo de cocção, percentual de perdas de peso e aproveitamento final de mariscos submetidos à cocção em água e sal.

\begin{tabular}{lccc}
\hline Mariscos & $\begin{array}{c}\text { Tempo de cocção } \\
\text { (minutos) }\end{array}$ & $\begin{array}{c}\text { Perdas de } \\
\text { Peso (\%) }\end{array}$ & $\begin{array}{c}\text { Aproveitamento } \\
\text { (\%) }\end{array}$ \\
\hline Camarão & 7 & 39,4 & 60,6 \\
Ostra & 20 & 14,4 & 85,6 \\
Lagosta & 20 & 14,4 & 85,6 \\
Caranguejo & 25 & 14,7 & 85,3 \\
Mexilhão & 35 & 10,2 & 89,8 \\
\hline
\end{tabular}

\section{3 - Análise de composição centesimal}

As determinações de umidade residual $\left(105^{\circ} \mathrm{C}\right)$, proteínas, lipídios e cinzas, foram realizadas em triplicatas de amostras, segundo métodos da AOAC [1]. A fração Nifext foi obtida pelo cálculo de diferença das outras frações analisadas. O valor calórico total foi calculado a partir dos coeficientes calóricos correspondentes para proteínas, lipídios e fração Nifext (como carboidratos), respectivamente 4,9 e $4 \mathrm{kcal} / \mathrm{g}$. Os resultados foram expressos de forma integral, considerando-se para ajustes de cálculo a umidade de secagem a $60^{\circ} \mathrm{C}$ do produto bruto cru ou cozido, acrescida da umidade residual após processamento para obtenção do pulverizado.

\section{4 - Análise de minerais}

As determinações de zinco, cobre e ferro foram feitas por espectrofotometria de absorção atômica, em triplicatas de amostras secas conforme ítem 2.2, oxidadas por via úmida, seguindo os procedimentos de pesagem, digestão e diluição especificados nas Tabelas 2, 3 e 4 .

A leitura foi realizada em espectrofotômetro de absorção atômica modelo Perkin Elmer ${ }^{*}$, , com lâmpada de cátodo ôco, calibrado em condições específicas de comprimento de onda, fenda e mistura dos gases para cada elemento. Foi utilizado o Tritisol Merck ${ }^{\circledR}$ diluído

(") Laboratório Instrumental da Divisão de Caracterização Química do IPEN - CNEN - SP em água desionizada nas concentrações distintas para cada análise. Os resultados obtidos em absorbância, após três leituras integradas de cada triplicata foram expressos em $\mathrm{mg} \%$ de amostra integral.

TABELA 2. Procedimentos de digestão via úmida para análise de zinco em mariscos da cidade de Natal-RN.

\begin{tabular}{|c|c|c|c|c|}
\hline Mariscos & $\begin{array}{c}\text { Quantidade } \\
\text { de amostra } \\
\text { (mg) }\end{array}$ & $\begin{array}{l}\text { Digestão:mistura } \\
\text { ácida/temperatura }\end{array}$ & $\begin{array}{c}\text { Diluição - água } \\
\text { desionizada } \\
(\mathrm{mL})\end{array}$ & $\begin{array}{c}\text { Proporção das } \\
\text { amostras } \\
\text { massa/volume } \\
\text { diluído (mg/mL) }\end{array}$ \\
\hline Camarão & 300 & $\begin{array}{c}9 \mathrm{~mL} \mathrm{HNO} \mathrm{HN}_{3}+3 \mathrm{~mL} \\
\mathrm{HClO}_{4}, 250^{\circ} \mathrm{C}\end{array}$ & 50 & 6 \\
\hline Caranguejo & 80 & $\begin{array}{c}6 \mathrm{~mL} \mathrm{HNO}_{3}+1 \mathrm{~mL} \\
\mathrm{HClO}_{4}, 250^{\circ} \mathrm{C}\end{array}$ & 100 & 0,8 \\
\hline Lagosta & 100 & $\begin{array}{c}6 \mathrm{~mL} \mathrm{HNO}_{3}+1 \mathrm{~mL} \\
\mathrm{HClO}_{4}, 250^{\circ} \mathrm{C}\end{array}$ & 50 & 2 \\
\hline Ostra & 100 & $\begin{array}{c}6 \mathrm{~mL} \mathrm{HNO}{ }_{3}+1 \mathrm{~mL} \\
\mathrm{HClO}_{4}, 250^{\circ} \mathrm{C}\end{array}$ & $1000 \mathrm{~mL}$ & 0,1 \\
\hline Mexilhão & 50 & $\begin{array}{c}6 \mathrm{~mL} \mathrm{HNO}_{3}+1 \mathrm{~mL} \\
\mathrm{HClO}_{4}, 250^{\circ} \mathrm{C}\end{array}$ & 100 & 0,5 \\
\hline
\end{tabular}

TABELA 3. Procedimentos de digestão via úmida para análise de ferro em mariscos da cidade de Natal-RN.

\begin{tabular}{|c|c|c|c|c|}
\hline Mariscos & $\begin{array}{c}\text { Quantidade } \\
\text { de amostra } \\
\text { (mg) }\end{array}$ & $\begin{array}{l}\text { Digestão:mistura } \\
\text { ácida/temperatura }\end{array}$ & $\begin{array}{l}\text { Diluição - água } \\
\text { desionizada } \\
(\mathrm{mL})\end{array}$ & $\begin{array}{c}\text { Proporção das } \\
\text { amostras } \\
\text { massa/volume } \\
\text { diluído ( } \mathrm{mg} / \mathrm{mL} \text { ) }\end{array}$ \\
\hline Camarão & 300 & $\begin{array}{c}9 \mathrm{~mL} \mathrm{HNO}_{3}+3 \mathrm{~mL} \\
\mathrm{HClO}_{4}, 200^{\circ} \mathrm{C}\end{array}$ & 50 & 6,0 \\
\hline Caranguejo & 350 & 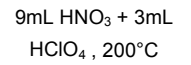 & 25 & 14,0 \\
\hline Lagosta & 700 & $\begin{array}{c}12 \mathrm{~mL} \mathrm{HNO}_{3}+3 \mathrm{~mL} \\
\mathrm{HClO}_{4}, 200^{\circ} \mathrm{C}\end{array}$ & 25 & 28,0 \\
\hline Ostra & 100 & $\begin{array}{c}6 \mathrm{~mL} \mathrm{HNO}_{3}+1 \mathrm{~mL} \\
\mathrm{HClO}_{4}, 200^{\circ} \mathrm{C}\end{array}$ & 100 & 1,0 \\
\hline Mexilhão & 70 & $\begin{array}{c}6 \mathrm{~mL} \mathrm{HNO}_{3}+1 \mathrm{~mL} \\
\mathrm{HClO}_{4}, 200^{\circ} \mathrm{C}\end{array}$ & 100 & 0,7 \\
\hline
\end{tabular}

TABELA 4. Procedimentos de digestão via úmida para análise de cobre em mariscos da cidade de Natal-RN

\begin{tabular}{|c|c|c|c|c|}
\hline Mariscos & $\begin{array}{c}\text { Quantidade } \\
\text { de amostra } \\
\text { (mg) }\end{array}$ & $\begin{array}{c}\text { Digestão:mistura } \\
\text { ácida/temperatura }\end{array}$ & $\begin{array}{c}\text { Diluição - água } \\
\text { desionizada } \\
(\mathrm{mL})\end{array}$ & $\begin{array}{c}\text { Proporção das } \\
\text { amostras } \\
\text { massa/volume } \\
\text { diluído ( } \mathrm{mg} / \mathrm{mL} \text { ) }\end{array}$ \\
\hline Camarão & 300 & $\begin{array}{c}6 \mathrm{~mL} \mathrm{HNO}_{3}+1 \mathrm{~mL} \\
\mathrm{HClO}_{4}, 250^{\circ} \mathrm{C}\end{array}$ & 50 & 6,0 \\
\hline Caranguejo & 300 & $\begin{array}{c}9 \mathrm{~mL} \mathrm{HNO} \mathrm{HN}_{3}+1 \mathrm{~mL} \\
\mathrm{HCIO}_{4}, 200^{\circ} \mathrm{C}\end{array}$ & 50 & 6,0 \\
\hline Lagosta & 300 & $\begin{array}{c}9 \mathrm{~mL} \mathrm{HNO}{ }_{3}+1 \mathrm{~mL} \\
\mathrm{HCIO}_{4}, 200^{\circ} \mathrm{C}\end{array}$ & 25 & 6,0 \\
\hline Ostra & 100 & $\begin{array}{c}6 \mathrm{~mL} \mathrm{HNO}_{3}+1 \mathrm{~mL} \\
\mathrm{HClO}_{4}, 200^{\circ} \mathrm{C}\end{array}$ & 100 & 1,0 \\
\hline Mexilhão & 70 & $\begin{array}{c}6 \mathrm{~mL} \mathrm{HNO}_{3}+1 \mathrm{~mL} \\
\mathrm{HClO}_{4}, 200^{\circ} \mathrm{C}\end{array}$ & 100 & 0,7 \\
\hline
\end{tabular}

O controle das variáveis metodológicas para minerais foi feito com material certificado do Bureau Community Bureau of Reference - BCR 185.

\section{3 - RESULTADOS E DISCUSSÃO}

Os resultados da composição centesimal e de minerais encontram-se nas Tabelas 5 e 6, os quais estão incluídos na Tabela de Composição de Alimentos Brasileira (www.fcf.usp.br/tabela). 
TABELA 5. Composição centesimal (g \%) e calórica de mariscos crus e cozidos consumidos na cidade de Natal-RN. (Média \pm DP)

\begin{tabular}{lcccccc}
\hline \multicolumn{1}{c}{ Mariscos } & Umidade & Proteinas & Lipideos & Cinzas & $\begin{array}{c}\text { Fracão Calorias } \\
\text { Nifext }\end{array}$ \\
\hline Camarão cru & 88,34 & $10,62 \pm 0,09$ & $0,36 \pm 0,03$ & $1,05 \pm 0,01$ & 0,00 & 45,72 \\
Camarão cozido & 81,60 & $16,78 \pm 0,02$ & $1,55 \pm 0,25$ & $1,25 \pm 0,02$ & 0,00 & 81,07 \\
Caranguejo cru & 84,42 & $13,30 \pm 0,47$ & $0,49 \pm 0,03$ & $0,71 \pm 0,00$ & 1,08 & 61,93 \\
Caranguejo cozido & 82,80 & $15,01 \pm 0,32$ & $0,28 \pm 0,02$ & $1,01 \pm 0,06$ & 0,90 & 66,16 \\
Lagosta crua & 76,26 & $21,38 \pm 0,05$ & $0,66 \pm 0,06$ & $1,57 \pm 0,05$ & 0,13 & 91,98 \\
Lagosta cozida & 78,34 & $19,04 \pm 0,29$ & $0,74 \pm 0,04$ & $1,80 \pm 0,03$ & 0,08 & 83,14 \\
Ostra crua & 79,71 & $14,19 \pm 0,19$ & $1,79 \pm 0,07$ & $1,36 \pm 0,02$ & 2,95 & 84,67 \\
Ostra cozida & 76,97 & $15,82 \pm 0,44$ & $2,62 \pm 0,12$ & $1,69 \pm 0,14$ & 2,90 & 98,46 \\
Mexilhão cru & 81,58 & $12,67 \pm 0,12$ & $1,10 \pm 0,11$ & $2,12 \pm 0,01$ & 2,53 & 70,70 \\
Mexilhão cozido & 83,89 & $11,24 \pm 0,21$ & $0,92 \pm 0,07$ & $1,76 \pm 0,01$ & 2,19 & 62,00
\end{tabular}

TABELA 6. Conteúdo de zinco, ferro e cobre em amostras integrais de mariscos crus e cozidos da cidade de Natal-RN.

\begin{tabular}{lccc}
\hline Mariscos & Zinco $\mathbf{( m g} \%)$ & Ferro $\mathbf{( m g} \%)$ & Cobre $(\mathbf{m g} \%)$ \\
\hline Camarão cru & $0,46 \pm 0,00$ & $1,16 \pm 0,15$ & $0,19 \pm 0,01$ \\
Camarão cozido & $1,05 \pm 0,03$ & $3,21 \pm 0,03$ & $0,60 \pm 0,01$ \\
Caranguejo cru & $6,56 \pm 0,34$ & $1,51 \pm 0,10$ & $1,11 \pm 0,02$ \\
Caranguejo cozido & $6,62 \pm 0,54$ & $1,33 \pm 0,15$ & $1,11 \pm 0,01$ \\
Lagosta crua & $1,93 \pm 0,15$ & $0,50 \pm 0,02$ & $0,39 \pm 0,01$ \\
Lagosta cozida & $1,81 \pm 0,23$ & $0,37 \pm 0,01$ & $1,75 \pm 0,01$ \\
Ostra crua & $66,10 \pm 2,30$ & $17,03 \pm 0,20$ & $2,49 \pm 0,16$ \\
Ostra cozida & $78,50 \pm 2,25$ & $21,20 \pm 1,50$ & $3,09 \pm 0,03$ \\
Mexilhão cru & $5,60 \pm 0,64$ & $40,10 \pm 0,44$ & $7,57 \pm 0,29$ \\
Mexilhão cozido & $2,99 \pm 0,03$ & $37,80 \pm 1,77$ & $3,70 \pm 0,16$ \\
\hline
\end{tabular}

\section{1 - Composição centesimal}

Dos resultados obtidos (Tabela 5) podemos observar que os mariscos apresentaram alto teor de umidade variando de 76 a $88 \%$. Os teores de proteína variaram de 10,6 a $21,4 \%$, sendo a lagosta o marisco que apresentou maior valor: 21,3 e 19,0\%, crua e cozida, respectivamente. Camarão, caranguejo e ostra apresentaram aumento da fração protéica com a cocção, em função da perda de água proveniente deste processamento. Podemos observar na Tabela 1, que o camarão mesmo cozido em menor tempo, apresentou maior percentual de perdas (39\%), conseqüentemente foi o marisco que mais concentrou proteínas (cru $=10,6$ para cozido $=16,8 \%$ ). Estes dados são relevantes para o cálculo de dietas, pois a falta de especificação quanto ao processamento dos alimentos, mesmo uma simples cocção caseira, pode resultar em estimativas erradas de consumo de nutrientes.

As concentrações de lipídios de um modo geral foram baixas. Em relação à fração cinzas, a cocção influenciou da mesma forma aumentando os valores com única exceção para o mexilhão que diminuiu de 2,12 para $1,76 \%$.

\section{2 - Minerais}

Observamos que houve uma variabilidade nos teores de zinco dos mariscos estudados (Tabela 6). A ostra destacou-se como a maior fonte deste mineral, cujos valores correspondem cerca de 5 vezes a necessidade diária de zinco para adultos (15mg/dia). Estudos anteriores demonstraram que a ostra além de ser uma fonte abundante de zinco, destaca-se também pela alta biodisponibilidade, provavelmente devido a sua forma química no músculo e estabilidade diante do processamento térmico [7].

A cocção não influenciou no conteúdo de zinco para o caranguejo e a lagosta; aumentou para o camarão e ostra; já no mexilhão ocorreu uma perda ao redor de $50 \%$. Estes dados sugerem que a cocção pode ter influído aumentando o teor de zinco das amostras de duas maneiras: pela perda de umidade, concentrando este mineral no alimento; ou pela presença de compostos ligantes dos minerais no alimento, que impediram sua perda pela água de cocção. A diminuição dos teores de zinco poderia ser explicada pela presença de compostos solúveis complexantes do zinco, ou mesmo na forma livre, que poderiam ser perdidos pela água de cocção. Nos sistemas biológicos o zinco se encontra predominantemente em estado divalente formando complexos em disposição tetrahédrica com aminoácidos, pepetídeos e nucleotídeos. Portanto, o conhecimento detalhado da especiação destes nutrientes na matriz alimentar é o que pode explicar melhor estes eventos [8].

Constatamos dentre os mariscos estudados que os moluscos apresentaram as maiores concentrações de ferro, ocupando o primeiro lugar o mexilhão, seguido da ostra. Nos crustáceos os valores foram inferiores, e dentre estes foi a lagosta que apresentou menor teor de ferro. A cocção influiu na composição destes mariscos, aumentando o teor de ferro na ostra e camarão, diminuindo na lagosta e mexilhão, e, no caso do caranguejo pouco se alterou.

O ferro foi o único mineral possível de se fazer uma análise comparativa entre os dados obtidos neste estudo e as tabelas de composição nacionais e estrangeiras. Ao se comparar os teores de ferro dos mariscos, com os dados das tabelas do ENDEF, FRANCO [2] e MC CANCE \& WIDDOWSON'S [5], encontramos algumas semelhanças, bem como valores discrepantes que poderão influir em estimativas erradas de consumo de ferro. O valor no camarão cru $(1,16 \mathrm{mg} \%)$ está próximo do citado na tabela do ENDEF [3], 1,6mg\%; e FRANCO [2], 1,4mg\%; porém, muito inferior ao de MC CANCE [5], 2,6mg\%. No caranguejo cozido encontramos 1,33mg $\mathrm{Fe} \%$, semelhante ao dado de MC CANCE [5], 1,3mg\%. A lagosta crua apresentou teor de $\mathrm{Fe}$ igual a $0,50 \mathrm{mg} \%$, próximo ao de FRANCO [2], 0,40mg\%, e bem inferior ao da tabela do ENDEF que é de $1,0 \mathrm{mg} \%$. No caso da lagosta cozida verificamos um valor de $0,37 \mathrm{mg} \mathrm{Fe} \%$, cerca de $50 \%$ menor que o de FRANCO [2] $(0,76 \mathrm{mg} \%)$ e o de MC CANCE [5] $(0,80 \mathrm{mg} \%)$. A análise de ferro na ostra crua resultou no dado mais distinto, pois a concentração de 17,0mg Fe\% foi muito superior aos correspondentes nas tabelas comparadas: FRANCO [2], $5,8 \mathrm{mg} \%$ e ENDEF, 7,2mg\%.

Quanto ao cobre, o mexilhão destacou-se como alimento mais rico, seguido pela ostra, sendo que para este 
primeiro a cocção influenciou bastante, provocando perdas de $50 \%$ no conteúdo deste mineral. Comportamento semelhante foi verificado neste mesmo marisco em relação ao zinco. O caranguejo, apesar de baixa concentração de cobre, manteve seus teores com a cocção.

No contexto geral deste estudo, a ostra e o mexiIhão se apresentaram como mariscos mais ricos dentre os minerais analisados.

\section{4 - CONCLUSÕES}

- Os mariscos analisados são fontes alimentares consideráveis de proteínas e minerais, com baixos teores lipídicos e calóricos.

- A cocção influiu de modo expressivo na composição em nutrientes destes alimentos.

- A ostra, o mexilhão e o caranguejo são fontes significativas de zinco, sendo a ostra a mais expressiva.

- A ostra e o mexilhão se destacaram também como melhores fontes de ferro e cobre.

\section{5 - REFERÊNCIAS BIBLIOGRÁFICAS}

[1] ASSOCIATION OF OFFICIAL ANALYTICAL CHEMISTS. Official Methods of Analysis. Arlington, AOAC, 1984.

[2] FRANCO, G.V.E. Nutrição. Texto Básico e Tabela de Composição Química de Alimentos. 6. ed. São Paulo. Livraria Atheneu, 1982, p. 226.
[3] Fundação IBGE - Secretaria de Planejamento da Presidência da República. Estudo Nacional da Despesa Familiar (ENDEF), Consumo Alimentar. Despesas das Famílias. Rio de Janeiro, IBGE, 1977. 201p.

[4] LAJOLO, F.M.; VANUCCHI, H. Tabelas de composição de nutrientes em alimentos: situação no Brasil. Archivos Latinoamericanos de Nutricion, v. 37, n. 4, p. 703-713, 1987.

[5] McCANCE, R.A., WIDDOWSON'S, E.M. The composition of foods. Royal Society of Chemistry and Ministry of Agriculture Fisheries and Food. 5 rev. 1991.

[6] National Research Council (1989). Recommended Dietary Allowances 10th. National Academy of Sciences, Washington, D.C.

[7] SOLOMONS, N.W.; JACOB, R.A. Studies on the bioavailability of zinc in humans: effects of heme and nonheme iron on the absorption of zinc. American Journal of Clinical Nutrition. v. 34, p. 475-482, 1981.

[8] SOUTHGATE, D. A.T. Trace elements: databases and food composition compilations. Food Chemistry, v. 43, p. 289293, 1992.

[9] TORRES, M.A.A., LOBO, N.F., SATO, K., QUEIROZ, S.S. Fortificação do leite fluido na prevenção e tratamento da anemia carencial ferropriva em crianças menores de 4 anos. Revista de Saúde Pública, v. 30, n. 4, p. 350$357,1996$.

[10] UAUY, R., OLIVARES, M., GONZALEZ, M. Essentiality of copper in humans. American Journal Clinical Nutrition, v. 67, p. 952 S-959S, 1998. 